\title{
Efficacy of the nicotine vaccine 3'-AmNic-rEPA (NicVAX) co-administered with varenicline and counselling for smoking cessation: a randomized placebo-controlled trial
}

Citation for published version (APA):

Hoogsteder, P. H. J., Kotz, D., van Spiegel, P. I., Viechtbauer, W., \& van Schayck, O. C. P. (2014). Efficacy of the nicotine vaccine 3'-AmNic-rEPA (NicVAX) co-administered with varenicline and counselling for smoking cessation: a randomized placebo-controlled trial. Addiction, 109(8), 1252-1259. https://doi.org/10.1111/add.12573

Document status and date:

Published: 01/08/2014

DOI:

10.1111/add. 12573

Document Version:

Publisher's PDF, also known as Version of record

\section{Document license:}

Taverne

Please check the document version of this publication:

- A submitted manuscript is the version of the article upon submission and before peer-review. There can be important differences between the submitted version and the official published version of record. People interested in the research are advised to contact the author for the final version of the publication, or visit the DOI to the publisher's website.

- The final author version and the galley proof are versions of the publication after peer review.

- The final published version features the final layout of the paper including the volume, issue and page numbers.

Link to publication

\footnotetext{
General rights rights.

- You may freely distribute the URL identifying the publication in the public portal. please follow below link for the End User Agreement:

www.umlib.nl/taverne-license

Take down policy

If you believe that this document breaches copyright please contact us at:

repository@maastrichtuniversity.nl

providing details and we will investigate your claim.
}

Copyright and moral rights for the publications made accessible in the public portal are retained by the authors and/or other copyright owners and it is a condition of accessing publications that users recognise and abide by the legal requirements associated with these

- Users may download and print one copy of any publication from the public portal for the purpose of private study or research.

- You may not further distribute the material or use it for any profit-making activity or commercial gain

If the publication is distributed under the terms of Article 25fa of the Dutch Copyright Act, indicated by the "Taverne" license above, 


\title{
Efficacy of the nicotine vaccine 3 '-AmNic-rEPA (NicVAX) co-administered with varenicline and counselling for smoking cessation: a randomized placebo-controlled trial
}

\author{
Philippe H. J. Hoogsteder', Daniel Kotz', Paul I. van Spiegel', Wolfgang Viechtbauer ${ }^{3}$ \& \\ Onno C. P. van Schayck' \\ CAPHRI School for Public Health and Primary Care, Department of Family Medicine, Maastricht University, Maastricht, the Netherlands,' Department of \\ Pulmonary Medicine, Slotervaart Hospital, Amsterdam, the Netherlands ${ }^{2}$ and School for Mental Health and Neuroscience, Department of Psychiatry and \\ Psychology, Maastricht University, Maastricht, the Netherlands ${ }^{3}$
}

\begin{abstract}
Background and Aims Nicotine vaccination has been proposed as a possible treatment to aid smoking cessation. First efficacy results of the nicotine vaccine 3'-AmNic-rEPA (NicVAX) showed that only a subgroup of the top 30\% antibody responders achieved higher abstinence rates than placebo. The present study examined the efficacy of adding NicVAX versus placebo to varenicline and behavioural support as an aid in smoking cessation and relapse prevention. Design Randomized placebo-controlled trial. Setting Two research centres (Maastricht University Medical Centre and Slotervaart Hospital) in the Netherlands. Participants A total of 558 smokers were assigned randomly to six injections with NicVAX $(n=278)$ or placebo $(n=280)$ both co-administered with open label varenicline and behavioural support. Measures Outcomes were prolonged carbon monoxide-validated abstinence from weeks 9 to 52 (primary) and weeks 37 to 52 (secondary). We also performed a pre-planned subgroup analysis in the top 30\% antibody responders. Findings There was no difference in abstinence rates between NicVAX and placebo from weeks 9 to 52 [27.7 versus $30.0 \%$, odds ratio $(\mathrm{OR})=0.89,95 \%$ confidence interval $(\mathrm{CI})=0.62-1.29]$ or weeks 37 to 52 (33.8 versus $33.2 \%, \mathrm{OR}=1.03,95 \% \mathrm{CI}=0.73-1.46)$. The top $30 \%$ antibody responders, compared to the placebo group, showed a non-significant tendency towards higher abstinence rates from weeks 37 to 52 (42.2 versus $33.2 \%$, $\mathrm{OR}=1.47,95 \% \mathrm{CI}=0.89-2.42$ ). Conclusion The nicotine vaccine, NicVAX, does not appear to improve the chances of stopping smoking when given in addition to varenicline and behavioural support.
\end{abstract}

Keywords Efficacy, immunogenicity, nicotine vaccine, placebo, randomized, safety, trial.

Correspondence to: Philippe H. J. Hoogsteder, CAPHRI School for Public Health and Primary Care, Department of Family Medicine, Maastricht University, PO Box 616, 6200MD Maastricht, the Netherlands. E-mail: philippe.hoogsteder@maastrichtuniversity.nl

Submitted 19 September 2013; initial review completed 17 December 2013; final version accepted 31 March 2014

\section{INTRODUCTION}

Approximately 1 billion people smoke tobacco worldwide, and their number is still increasing [1]. Tobacco smoking is a major risk factor for morbidity and mortality and it is therefore important to stop smoking [2,3]. Compared with unaided quitting, currently available evidence-based smoking cessation treatments such as nicotine replacement therapies, antidepressants and partial nicotine receptor agonists, combined with behav- ioural support, increase abstinence rates up to a maximum of $20-25 \%$ after 1 year of follow-up [4-8].

A promising treatment in smoking cessation is the concept of nicotine vaccination: active immunization against the non-immunogenic nicotine molecule, which for this purpose is linked to a carrier protein [9]. After the first injection the immune system becomes activated to produce nicotine-specific antibodies. These circulating antibodies, that theoretically yield longer-lasting therapeutic effects than currently available cessation aids, bind 
to the nicotine molecules during smoking at the moment they enter the bloodstream, and form an antigenantibody complex that is too large to cross the bloodbrain barrier [9]. Whereas available pharmacotherapies focus mainly upon reducing symptoms of withdrawal and craving during a quit attempt, nicotine vaccines prevent large amounts of nicotine molecules from reaching the central nervous system, and thereby attenuate the rewarding effect of nicotine during smoking [10]. Previously published data about nicotine vaccines concluded that there was no compensatory smoking in vaccinated smokers [11].

Although multiple nicotine vaccines are currently under development, previously published results about the efficacy of vaccines such as 3'-AmNic-rEPA (NicVAX) (Nabi Biopharmaceuticals, Rockville, MD, USA) or Nicotine-QB (Cytos Biotechnology, Schlieren, Switzerland) compared with placebo showed disappointing results [11]. Only a subgroup of the top 30\% antibody responders receiving NicVAX or Nicotine-QB achieved significantly higher abstinence rates than the placebo group at both 6- and 12-month follow-up [11]. All nicotine vaccines are currently under development and not yet available on the market for smoking cessation.

While previous research focused on the value of nicotine vaccines as an aid for smoking cessation [11], we designed the first study to investigate the potential of NicVAX in preventing relapse by combining nicotine vaccination with behavioural support and with the partial nicotine receptor agonist varenicline, which reduces craving and withdrawal symptoms during the first weeks of a quit attempt. After the 12-week treatment with varenicline nicotine-specific antibody concentrations should, in theory, be high enough to decrease the chance of a full-blown relapse in smokers who initially quit smoking.

This randomized, placebo-controlled trial was conducted to investigate the efficacy of the nicotine conjugate vaccine NicVAX co-administered with a 12-week treatment of varenicline and counselling in helping smokers to quit smoking and preventing relapse over a follow-up period of 1 year.

\section{METHODS}

\section{Study design}

This Phase IIb randomized, double-blinded, parallel-arm, placebo-controlled trial was conducted at Maastricht University Medical Centre and Slotervaart Hospital Amsterdam, the Netherlands, from November 2009 to August 2012. A detailed description of the trial design has been published elsewhere [12].

The trial was approved by the Dutch Central Committee on Research Involving Human Participants (CCMO-
NL25046.000.08) and the Dutch Ministry of Health, Welfare and Sports. The trial was conducted according to the standards of good clinical practice. The trial is registered at ClinicalTrials.gov (NCT00995033). To conduct this trial we received a TOP-grant from the Netherlands Organization for Health Research and Development (ZonMW). The study medication was sponsored by Nabi Biopharmaceuticals and Pfizer.

\section{Study population}

We included men and women aged between 18 and 65 years who smoked at least 10 cigarettes a day, were in good general health and had an alveolar carbon monoxide level of $\geq 8$ parts per million (p.p.m.). In addition, we included women who had a negative urine pregnancy test and intended to use appropriate birth control during the study participation.

Exclusion criteria were: prior exposure to NicVAX, known allergies to components of the vaccine, clinically significant allergies, use of systemic steroids, history of cancer 60 months prior to randomization, HIV or other acquired immunodeficiencies, history of drug or alcohol abuse, psychiatric disorders 3 months prior to randomization, the use of antidepressants, antipsychotics, mood stabilizers or naltrexone, clinically significant cardiovascular disease 6 months prior to randomization, hepatic or renal impairment, body mass index $>38 \mathrm{~kg} /$ $\mathrm{m}^{2}$, use of smoking cessation treatment 30 days prior to randomization, intolerance to varenicline, use of other tobacco products than cigarettes, use of botox injections 30 days prior to randomization, use of any investigation vaccine 30 days prior to randomization, previous serious unexpected adverse reactions to a vaccine and the receipt of an investigational drug or device 30 days prior to randomization.

\section{Randomization and interventions}

Eligible participants were randomized at week -2 using an interactive web response system in a $1: 1$ ratio (block size of four participants) to an experimental group receiving six injections with $400 \mu \mathrm{g}$ NicVAX or a control group receiving six placebo injections at weeks $-2,2,6,10,14$ and 24. The Supporting information (Fig. S1) illustrates an overview of the study design.

The randomization system assigned unique syringe numbers corresponding to the randomized treatment. To guarantee appropriate blinding, all syringes with NicVAX, as well as the placebo syringes, had an identical appearance. Participants and investigators remained blinded to the randomization until the database was locked after the final visit of the last participant.

NicVAX consisted of $400 \mu \mathrm{g}$ of purified 3'aminomethylnicotine conjugated to the r-Exoprotein A 
(rEPA) of Pseudomonas aeruginosa, adsorbed to $1.2 \mathrm{mg}$ aluminium (Alhydrogel 85) in $1 \mathrm{ml}$ phosphate-buffered saline $(0.15 \mathrm{~mol} / \mathrm{l} \mathrm{NaCl}, 0.002 \mathrm{~mol} / \mathrm{l} \mathrm{NaPO} 4, \mathrm{pH} 7.2$, $0.01 \%$ polysorbate 80 ). The placebo product consisted of a $1 \mathrm{ml}$ solution with phosphate-buffered saline and $1.2 \mathrm{mg}$ Alhydrogel 85 [13].

Both the experimental and the control groups received a 12-week treatment with open-label varenicline starting at week 0 , together with 23 behavioural support sessions during 54 weeks of follow-up. The behavioural support sessions consisted of a standardized protocol based on motivational interviewing [12]. Varenicline treatment started with 3 days of $0.5 \mathrm{mg}$ once a day, followed by 4 days of $0.5 \mathrm{mg}$ twice a day, and thereafter 11 weeks of $1.0 \mathrm{mg}$ twice a day. The target quit date was set at 1 week after initiation of varenicline treatment. Face-to-face and telephonic behavioural support was based on motivational interviewing and performed by a trained research assistant with a planned duration of approximately 10 minutes [14].

\section{Measurements}

Smoking status and cigarette consumption were reported by the participant on a weekly basis. Self-reported nonsmoking was validated by exhaled carbon monoxide (CO) (MicroCO; Micro Medical Ltd, Basingstoke, UK) measurements at weeks 10, 12, 14, 18, 24, 28, 34, 40, 46 and 52.

To analyse immunogenicity we collected 13 serum samples to measure anti-nicotine immunoglobulin (Ig)G antibody concentrations, using an enzyme-linked immunosorbent assay [15].

For safety purposes, we collected the intensity and drug relationship of local and systemic post-injection reactions for 7 days. Further, adverse events (AEs) were collected using the Medical Dictionary for Regulatory Activities [16].

Withdrawal symptoms were measured using the Minnesota Nicotine Withdrawal Scale (MNWS) at screening, week 2, weeks 12-15, weeks 26-29 and weeks 49-52 [17]. The Fagerström Test for Cigarette Dependence (FTCD) was collected at screening, weeks -2, 24 and 52 for non-abstinent participants [18].

\section{Efficacy outcome measures}

We defined the primary outcome as continuous abstinence from weeks 9 to 52. Secondary efficacy measures were abstinence from weeks 37 to 52 , abstinence from weeks 9 to 24 and 7-day point-prevalence abstinence at weeks 12, 26 and 52.

According to our statistical analysis plan, we compared the abstinence rates of the top 25\% and top 50\% antibody responder groups with the placebo group [12].
Contrary to our study protocol, additional efficacy analyses were based on a subgroup of the top 30\% antibody responders, instead of the top 33\%, as this was the group that had significantly higher abstinence rates in a previous trial using NicVAX [13].

A participant was considered a non-smoker when (s)he reported not smoking, not using nicotine replacement therapy and when non-smoking status was confirmed by a CO measurement <10 p.p.m. In those circumstances where there was a discrepancy between the smoker's self-report and the corresponding CO measurement, the most conservative outcome was used and the participant was defined as a smoker for that specific week. Participants were not allowed to miss two consecutive $\mathrm{CO}$ measurements or more than four consecutive weekly self-reports, otherwise the smoking status for these weeks was imputed as being non-abstinent. In all other cases the smoking status was imputed using either bordering $\mathrm{CO}$ measurements or self-reports.

\section{Statistical analysis}

To analyse efficacy, safety and immunogenicity data, we used the intention-to-treat (ITT) population, defined as all participants who were randomized and received at least one injection with NicVAX or placebo. Efficacy analyses were performed primarily with a partially unblinded database, with two groups (A and B) not knowing which letter was assigned to what treatment arm.

For the efficacy analyses, we compared NicVAX with placebo using a logistic regression model. For postinjection reaction analyses, we compared the percentages, intensity and/or drug relationship using Fisher's exact test. The incidence of mild, moderate and severe AEs was compared between the two groups using a Poisson regression model, accounting for any potential overdispersion by estimating the scale parameter as the ratio of the deviance to the degrees of freedom. The same method was used to compare the incidence of AEs related to NicVAX, to varenicline and to both.

Additionally, we calculated the top 30\% antibody responders of the group that received NicVAX, using the trapezoidal rule in an area under the curve analysis from weeks -2 to 24 without imputation of missing data. Abstinence outcomes of these top responders were compared with the placebo group using logistic regression analysis.

Nicotine withdrawal symptoms, nicotine dependence and cigarette consumption were analysed using analysis of covariance (ANCOVA). For nicotine withdrawal symptoms, multiple scores were averaged over the collection period and hence a weighted ANCOVA was used, with weights equal to the number of non-missing values. Statistical analyses were performed using SPSS ${ }^{\circledR}$ version 19. 


\section{Sample size calculation}

To detect a clinically relevant difference of at least $12 \%$ abstinence between NicVAX and placebo (34 versus $22 \%$, respectively), with $90 \%$ power and a $5 \%$ type 1 error probability, 300 participants per treatment arm were needed. The abstinence rate in the placebo group was based on published trials about the efficacy of varenicline [19,20].

\section{RESULTS}

\section{Study population}

Although we planned primarily to recruit 300 participants per treatment arm within a 1-year period, we had to extend the recruitment period by almost 1 year to finally include 558 smokers $(n=384$ at the Maastricht site, $n=174$ at the Amsterdam site). A total of 278 smokers were assigned randomly to NicVAX and 280 to the placebo (Fig. 1). Participants' characteristics in both groups were comparable at baseline (Table 1). Overall, $75 \%$ of all participants completed the 54 weeks of follow-up (dropout rates were $25.9 \%$ in the NicVAX group and $25.0 \%$ in the placebo group). There was no statistically significant difference in attrition rates between the groups [odds ratio $(\mathrm{OR})=0.95,95 \%$ confidence interval $(\mathrm{CI})=0.65-1.40]$. All 558 randomized participants received the first injection, and 546 (97.8\%), $515(92.2 \%), 487(87.3 \%), 462(82.2 \%)$ and 426 (76.3\%) received the second, third, fourth, fifth and sixth injections, respectively.

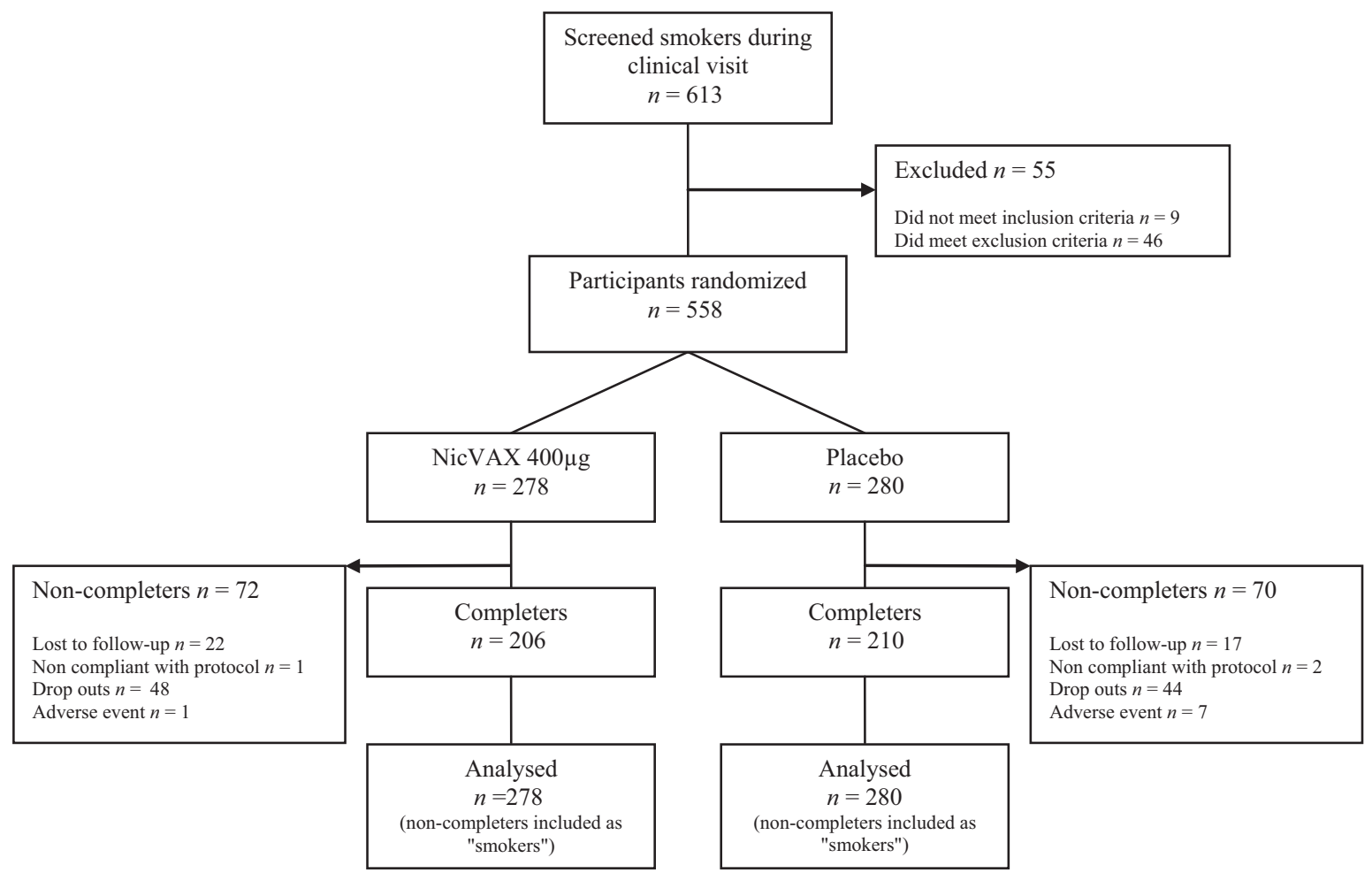

Figure I Flowchart of participants

Table 1 Characteristics of participants at baseline.

\begin{tabular}{lcc}
\hline & NicVAX $(n=278)$ & Placebo $(n=280)$ \\
\hline Male gender, $n(\%)$ & $130(46.8)$ & $119(42.5)$ \\
Age in years, mean \pm SD & $47.2 \pm 8.4$ & $47.6 \pm 8.9$ \\
Cigarettes per day, median (IQR) & $20(15.3 ; 24.4)$ & $20(16.8 ; 25.0)$ \\
FTCD score, mean \pm SD & $5.3 \pm 1.9$ & $5.4 \pm 2.0$ \\
Previous quit attempts, median (IQR) & $3(1 ; 5)$ & $2(1 ; 4)$ \\
\hline
\end{tabular}

FTCD = Fagerström Test for Cigarette Dependence; $\mathrm{SD}=$ standard deviation. Interquartile range (IQR) with 25\%; 75\% quartiles. 


\section{Efficacy}

Continuous abstinence from weeks 9 to 52 was $27.7 \%$ $(n=77)$ in the NicVAX group and $30.0 \%(n=84)$ in the placebo group. This difference was not statistically significant $(\mathrm{OR}=0.89,95 \% \mathrm{CI}=0.62-1.29)$. Also, the abstinence from weeks 37 to 52 was not significantly different between the NicVAX group and the placebo group (33.8 versus $33.2 \%$; $\mathrm{OR}=1.03,95 \% \mathrm{CI}=0.72-1.46$ ). All other outcome measures are presented in Table 2. Additionally, Fig. 2a shows the point-prevalence during the 54 weeks of follow-up between both treatment groups. There was no significant difference in withdrawal symptoms, nicotine dependence and cigarette consumption between both groups.

\section{Efficacy in the top $30 \%$ antibody responders}

The subgroup analyses of the top 30\% antibody responders $(n=83)$ revealed no statistically significant difference in abstinence rates compared with the placebo group $(n=280)$ from weeks 9 to 52 (33.7 versus 30.0\%,
$\mathrm{OR}=1.19,95 \% \mathrm{CI}=0.71-2.00)$. All other outcome measures within this subgroup are listed in Table 3. Figure $2 \mathrm{~b}$ illustrates the point-prevalence abstinence in the top 30\% antibody responder group compared with the placebo group. A model distinguishing three groups (top 30\% antibody responders, bottom 70\% antibody responders and the placebo group) did not provide a significantly better fit than a model with only two groups (NicVAX versus placebo).

We also compared the abstinence rates of the top $25 \%$ antibody responders and the top 50\% antibody responders with the placebo group. Detailed descriptions of these results are listed in the Supporting information (Table S1).

\section{Safety}

A summary of post-injection reactions is listed in Table 4. All separate post-injection reactions in a given category were combined for each participant over all injections. In general, local ache $(64.7 \%)$, tenderness $(84.9 \%)$ and systemic myalgia $(66.3 \%)$ were the most reported

Table 2 Abstinence in the NicVAX group compared to placebo.

\begin{tabular}{|c|c|c|c|}
\hline & $\begin{array}{l}\text { NicVAX }(n=278) \\
n(\%)\end{array}$ & $\begin{array}{l}\text { Placebo }(n=280) \\
n(\%)\end{array}$ & OR $(95 \% \mathrm{CI})$ \\
\hline Abstinence weeks 9 to 52 & $77(27.7)$ & $84(30.0)$ & $0.89(0.62-1.29)$ \\
\hline Abstinence weeks 37 to 52 & $94(33.8)$ & $93(33.2)$ & $1.03(0.72-1.46)$ \\
\hline Abstinence weeks 9 to 24 & $107(38.5)$ & $105(37.5)$ & $1.04(0.74-1.47)$ \\
\hline Point-prevalence week 12 & $193(69.4)$ & $187(66.8)$ & $1.13(0.79-1.61)$ \\
\hline Point-prevalence week 26 & $146(52.5)$ & $142(50.7)$ & $1.08(0.77-1.50)$ \\
\hline Point-prevalence week 52 & $118(42.2)$ & $107(38.2)$ & $1.20(0.85-1.68)$ \\
\hline
\end{tabular}

$\mathrm{OR}=$ odds ratio; $\mathrm{CI}=$ confidence interval .
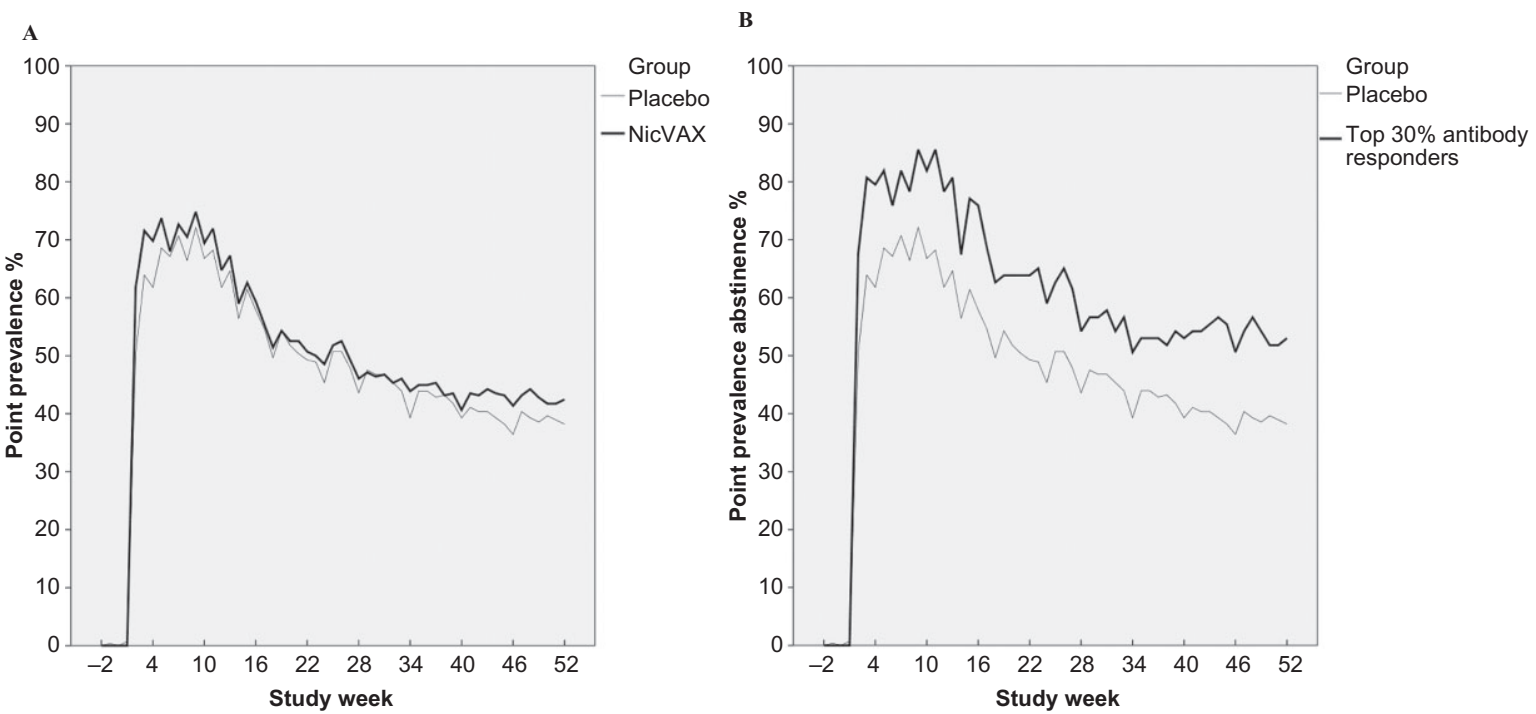

Figure 2 (a) Point-prevalence abstinence in the $\operatorname{NicVAX}(n=278)$ and the placebo group (280). (b) Point-prevalence abstinence of the top $30 \%$ antibody responders $(n=83)$ and the placebo group $(n=280)$ 
Table 3 Abstinence in the top 30\% antibody responders group compared with placebo.

\begin{tabular}{llrr}
\hline & $\begin{array}{l}\text { Top 30\% }(n=83) \\
n(\%)\end{array}$ & $\begin{array}{l}\text { Placebo }(n=280) \\
n(\%)\end{array}$ & OR (95\% CI) \\
\hline Abstinence weeks 9 to 52 & $28(33.7)$ & $84(30.0)$ & $1.19(0.71-2.00)$ \\
Abstinence weeks 37 to 52 & $35(42.2)$ & $93(33.2)$ & $1.47(0.89-2.42)$ \\
Abstinence weeks 9 to 24 & $40(48.2)$ & $105(37.5)$ & $1.55(0.95-2.54)$ \\
Point-prevalence week 12 & $68(81.9)$ & $187(66.8)$ & $1.26(1.22-4.16)$ \\
Point-prevalence week 26 & $54(65.1)$ & $107(30.09-3.01)$ \\
Point-prevalence week 52 & $44(53.0)$ & $1.82(1.11-2.99)$ \\
\hline
\end{tabular}

$\mathrm{OR}=$ odds ratio; $\mathrm{CI}=$ confidence interval.

Table 4 Summary of post-injection reactions by treatment group.

\begin{tabular}{lccc}
\hline & $\begin{array}{l}\text { NicVAX group } \\
\text { Number of } \\
\text { subjects (\%) }\end{array}$ & $\begin{array}{l}\text { Placebo group } \\
\text { Number of } \\
\text { subjects (\%) }\end{array}$ & P-value \\
\hline Local & & & \\
Ache & $192(69.1)$ & $169(60.4)$ & $*$ \\
Burning & $111(39.9)$ & $60(21.4)$ & $* * *$ \\
Erythema & $118(42.4)$ & $38(13.6)$ & $* * *$ \\
Heat & $94(33.8)$ & $33(11.8)$ & $* * *$ \\
Swelling/induration & $183(65.8)$ & $108(38.6)$ & $* * *$ \\
Tenderness & $242(87.1)$ & $232(82.9)$ & - \\
Systemic & & & \\
Myalgia & $199(71.6)$ & $171(61.1)$ & $* *$ \\
Headache & $120(43.2)$ & $113(40.4)$ & - \\
General discomfort & $131(47.1)$ & $113(40.4)$ & - \\
Nausea & $86(30.9)$ & $69(24.6)$ & - \\
Vomiting & $12(4.3)$ & $8(2.9)$ & - \\
& & & \\
\hline
\end{tabular}

${ }^{*} P<0.05,{ }^{* *} P<0.01,{ }^{* * *} P<0.001$.

post-injection reactions across both groups. Participants who received NicVAX injections reported significantly more local ache, burning, erythema, heat, swelling and systemic myalgia after vaccination compared to those who received placebo injections.

Table 5 gives an overview of the reported AEs and SAEs in both treatment groups. Participants reported 2145 AEs and 28 SAEs, while the majority of AEs were indicated as being of mild or moderate severity. Most frequently reported AEs across the two groups were headache (13.3\%), nasopharyngitis (7.5\%) and influenza (7.1\%). Significantly more AEs were related to NicVAX $(n=45)$ compared to placebo $(n=13)$. Most reported that NicVAX-related AEs were injection-site pain $(n=8)$, injection-site pruritis $(n=12)$ and injection-site swelling $(n=8)$. A group of $21.5 \%$ of the study population was intolerant to varenicline and discontinued the treatment prematurely [ $n=63(22.7 \%)$ in the NicVAX group compared with $n=57(20.4 \%)$ in the placebo group].
Table 5 Summary of (serious) adverse events by treatment group.

\begin{tabular}{|c|c|c|c|}
\hline & $\begin{array}{l}\text { NicVAX group } \\
\text { Number of } \\
\text { events (\%) }\end{array}$ & $\begin{array}{l}\text { Placebo group } \\
\text { Number of } \\
\text { events (\%) }\end{array}$ & $P$-value \\
\hline Total AEs & 1079 & 1066 & - \\
\hline Mild & $768(71.2)$ & $802(75.2)$ & - \\
\hline Moderate & $252(23.4)$ & $223(20.9)$ & - \\
\hline Severe & $59(5.5)$ & $41(3.8)$ & - \\
\hline $\begin{array}{l}\text { AEs related to } \\
\text { NicVAX }\end{array}$ & $45(4.2)$ & $13(1.2)$ & $* * *$ \\
\hline $\begin{array}{c}\text { AEs related to } \\
\text { varenicline }\end{array}$ & $130(12.0)$ & 147 (13.8) & - \\
\hline $\begin{array}{l}\text { AEs related to } \\
\text { both }\end{array}$ & $8(0.7)$ & $5(0.5)$ & - \\
\hline $\begin{array}{l}\text { (S)AEs leading to } \\
\text { discontinuation } \\
\text { NicVAX }\end{array}$ & $7(0.6)$ & $4(0.4)$ & - \\
\hline $\begin{array}{l}\text { (S)AEs leading to } \\
\text { discontinuation } \\
\text { varenicline }\end{array}$ & $63(5.8)$ & $57(5.3)$ & - \\
\hline SAEs $^{\mathrm{a}}$ & $13(1.2)$ & 15 (1.4) & - \\
\hline
\end{tabular}

$\mathrm{AE}=$ adverse event; $\mathrm{SAE}=$ serious adverse event. ${ }^{\text {aNone }}$ of the SAEs were related to the IP or varenicline. ${ }^{* * *} P<0.001$.

\section{DISCUSSION}

The results of this Phase IIb trial showed that NicVAX was not effective in increasing abstinence from smoking in smokers who were also treated with open-label varenicline and behavioural support. The outcomes of the current trial seem to be in line with previously reported results on the efficacy of NicVAX from two large Phase III trials [11]. Those trials showed that NicVAX was unable to significantly increase smoking abstinence compared to placebo from weeks 37 to 52 , with corresponding abstinence rates of $11 \%$ in both groups [11]. Possible reasons for the negative efficacy results may be related to the inability of NicVAX injections to elicit therapeutic levels of nicotine-specific antibodies in the ITT population [11]. As a consequence of the possible failure to induce 
adequate levels of antibodies in the majority of the trial participants, it is presumed that quitters who lapsed did not profit from the potential blockage of nicotine's rewarding effects. Furthermore, it is evident that the process of smoking cessation and relapse is more complex than the blockage of nicotine's effect on the activation of the reward centre [21]. However, it was remarkable that the abstinence rates we observed in both the NicVAX group $(27.7 \%)$ and the placebo group $(30.0 \%)$ from weeks 9 to 52 were higher than in trials using varenicline as a monotherapy for smoking cessation. Previously reported abstinence rates in varenicline trials for this specific period varied around 22\% [19,20]. This difference could be explained by the intensive behavioural support that we provided during our Phase IIb trial [8].

The additional analyses that we performed regarding abstinence rates in two subgroups of the top 50\% and top $25 \%$ antibody responders showed that high antibody levels in vaccinated smokers might be related to smoking abstinence. The top 50\% subgroup had significantly higher abstinence rates compared to placebo from weeks 9 to 24 and weeks 37 to 52 , which could be related to the larger sample size than the top $30 \%$ and the top $25 \%$ analyses. The results suggest that there could be a benefit from high serum antibody levels when NicVAX is combined with an effective cessation therapy such as varenicline. Despite that, our results could not confirm this benefit on continuous abstinence from weeks 9 to 52 either in the top $50 \%$ or the top $25 \%$ antibody responders.

Contrary to previously published results regarding the abstinence rates in a subgroup of the top 30\% antibody responders, we are the first to describe a non-significant difference in abstinence in this group compared with placebo at both 6 and 12 months of follow-up [11]. Although there is a tendency towards a statistically significant effect in this top responder group, the ORs we observed for continuous abstinence at 6 and 12 months $(\mathrm{OR}=1.55$ and 1.47 , respectively) were much lower than those observed in a previous trial investigating NicVAX $(\mathrm{OR}=2.69$ and 2.64) [13]. A reason could be that the effect of NicVAX over and above the effect of varenicline and behavioural support may have been too low to significantly increase abstinence. However, the analyses regarding the point-prevalence analyses showed a statistically significant effect at 12, 26 and 52 weeks of followup. The difference in point-prevalence abstinence seems to be caused by a significant increase in abstinence during the first 2 weeks after the quit attempt that is maintained until the end of the trial, which implies that one injection with NicVAX in antibody responders could have a beneficial effect on abstinence.

Our safety analyses showed that the combination of NicVAX with varenicline was well tolerated and safe. However, the group receiving NicVAX reported signifi- cantly more post-injection reactions such as local burning, erythema, heat, swelling and systemic myalgia compared to the group that received placebo injections. As far as we know, this is the first study reporting an association between NicVAX and local and systemic reactions, while previous studies did not discover a significant difference in these reactions compared with placebo [11].

A potential limitation regarding the design of this trial is that participants might have had insufficient antibody levels at the time of their quit attempt (week 1), a period in which the relapse rate peaked, and therefore smokers had no additional effect of the induced antibody response [22]. As the antibody response in the current trial showed a peak about 2 weeks after the fourth injection (week 12), it would have been better if smokers had planned their quit attempt during the corresponding week and started with varenicline treatment 1 week before. This therapeutic approach would imply several weeks of continued smoking and could be a major disadvantage for smokers who want to quit instantly after the start of NicVAX therapy. Therefore, participants enrolled into this Phase IIb trial continued using varenicline until study week 12 , when antibody levels were expected to be sufficient to prevent relapse (after the fourth injection). Despite the current design, NicVAX was shown to be ineffective to reduce relapse significantly from the end of varenicline treatment until 1-year follow-up, reflected in the abstinence from weeks 37 to 52 .

Several nicotine vaccines are currently under development [21]. The results from Phases II and III trials reported to date showed clearly that nicotine vaccination was ineffective in increasing abstinence outcomes significantly in the majority of smokers who want to quit. However, the same studies revealed a clear effect of high serum antibody levels on the chance to quit smoking successfully [11]. The development of immunotherapeutic agents for smoking cessation will be challenging, and should focus on the ability of the nicotine-specific antibodies to bind nicotine in the bloodstream, to elicit therapeutic levels of antibodies in the majority of smokers who want to quit and thereby prevent nicotine from reaching the brain during smoking [11].

To conclude, the results from this study confirm previous results on the lack of efficacy of NicVAX in combination with varenicline and behavioural support as a therapy for smoking cessation or relapse prevention when compared with varenicline and counselling alone in smokers who want to quit.

\section{Acknowledgements}

We would like to thank Linda de Boer, Anita Coumans, Hilde Bours, Pauline Horsten, Jeannique Kranenburg, 
Arja van de Voorde, Ilona van de Kolk, Roelof van der Westen and the research-team in Amsterdam for their assistance during the conduction of this trial. Furthermore we would like to thank Luc Gidding for being the examining physician. We also thank all trial participants for their active participation during this trial and ZonMW for receiving the TOP-grant to conduct this study.

\section{Clinical trial registration}

Trial registration number: ClinicalTrials.gov (NCT00995033).

\section{Declaration of interests}

D.K. received an unrestricted grant from Pfizer for a smoking cessation trial. P.v.S. received grants from, and served as a speaker and consultant for, Pfizer. O.v.S. received unrestricted grants from Pfizer and Boehringer Ingelheim. W.V. and P.H. have no conflicts of interest to declare.

\section{References}

1. World Health Organization. WHO report on the global tobacco epidemic 2011: warning about the dangers of tobacco. World Health Organization, 2011. Available at: http://whqlibdoc .who.int/publications/2011/9789240687813_eng.pdf (accessed 5 February 2013) (Archived at http:// www.webcitation.org/5Kt3PxfFl on 30 April 2014).

2. Thun M. J., Carter B. D., Feskanich D., Freedman N. D., Prentice R., Lopez A. D. et al. 50-year trends in smokingrelated mortality in the United States. N Engl J Med 2013; 368: 351-64.

3. Jha P., Ramasundarahettige C., Landsman V., Rostron B., Thun M., Anderson R. N. et al. 21st-century hazards of smoking and benefits of cessation in the United States. $N$ Engl J Med 2013; 368: 341-50.

4. Stead L. F., Perera R., Bullen C., Mant D., Hartmann-Boyce J., Cahill K. et al. Nicotine replacement therapy for smoking cessation. Cochrane Database Syst Rev 2012; (11): CD000146.

5. Hughes J. R., Stead L. F., Lancaster T. Antidepressants for smoking cessation. Cochrane Database Syst Rev 2007; (1): CD000031.

6. Cahill K., Stead L. F., Lancaster T. Nicotine receptor partial agonists for smoking cessation. Cochrane Database Syst Rev 2012; 4: CD006103.

7. West R., Zatonski W., Cedzynska M., Lewandowska D., Pazik J., Aveyard P. et al. Placebo-controlled trial of cytisine for smoking cessation. N Engl J Med 2011; 365: 1193-200.

8. Stead L. F., Lancaster T. Behavioural interventions as adjuncts to pharmacotherapy for smoking cessation. Cochrane Database Syst Rev 2012; (12): CD009670.

9. Cerny E. H., Cerny T. Vaccines against nicotine. Hum Vaccin 2009; 5: 200-5.

10. Pentel P., Malin D. A vaccine for nicotine dependence: targeting the drug rather than the brain. Respiration 2002; 69: 193-7.
11. Hartmann-Boyce J., Cahill K., Hatsukami D., Cornuz J. Nicotine vaccines for smoking cessation. Cochrane Database Syst Rev 2012; 8: CD007072.

12. Hoogsteder P. H., Kotz D., van Spiegel P. I., Viechtbauer W., Brauer R., Kessler P. D. et al. The efficacy and safety of a nicotine conjugate vaccine $(\operatorname{NicVAX}(\mathrm{R}))$ or placebo co-administered with varenicline (Champix $(\mathrm{R})$ ) for smoking cessation: study protocol of a phase IIb, double blind, randomized, placebo controlled trial. BMC Public Health 2012; 12: 1052.

13. Hatsukami D. K., Jorenby D. E., Gonzales D., Rigotti N. A., Glover E. D., Oncken C. A. et al. Immunogenicity and smoking-cessation outcomes for a novel nicotine immunotherapeutic. Clin Pharmacol Ther 2011; 89: 392-9.

14. Lai D. T., Cahill K., Qin Y., Tang J. L. Motivational interviewing for smoking cessation. Cochrane Database Syst Rev 2010; (3): CD006936.

15. Voller A. The enzyme-linked immunosorbent assay (ELISA) (theory, technique and applications). Ric Clin Lab 1978; 8: 289-98.

16. Bousquet C., Lagier G., Lillo-Le Louet A., Le Beller C., Venot A., Jaulent M. C. Appraisal of the MedDRA conceptual structure for describing and grouping adverse drug reactions. Drug Saf 2005; 28: 19-34.

17. Cappelleri J. C., Bushmakin A. G., Baker C. L., Merikle E., Olufade A. O., Gilbert D. G. Revealing the multidimensional framework of the Minnesota nicotine withdrawal scale. Curr Med Res Opin 2005; 21: 749-60.

18. Heatherton T. F., Kozlowski L. T., Frecker R. C., Fagerstrom K. O. The Fagerstrom Test for Nicotine Dependence: a revision of the Fagerstrom Tolerance Questionnaire. Br J Addict 1991; 86: 1119-27.

19. Jorenby D. E., Hays J. T., Rigotti N. A., Azoulay S., Watsky E. J., Williams K. E. et al. Efficacy of varenicline, an alpha4beta2 nicotinic acetylcholine receptor partial agonist, vs placebo or sustained-release bupropion for smoking cessation: a randomized controlled trial. JAMA 2006; 296: 56-63.

20. Gonzales D., Rennard S. I., Nides M., Oncken C., Azoulay S., Billing C. B. et al. Varenicline, an alpha4beta2 nicotinic acetylcholine receptor partial agonist, vs sustained-release bupropion and placebo for smoking cessation: a randomized controlled trial. JAMA 2006; 296: 47-55.

21. Raupach T., Hoogsteder P. H., Onno van Schayck C. P. Nicotine vaccines to assist with smoking cessation: current status of research. Drugs 2012; 72: e1-16.

22. Hughes J. R., Keely J., Naud S. Shape of the relapse curve and long-term abstinence among untreated smokers. Addiction 2004; 99: 29-38.

\section{Supporting information}

Additional Supporting Information may be found in the online version of this article at the publisher's web-site:

Figure S1 Overview study design.

Table S1 Abstinence in the top 50\% and top 25\% antibody responders compared to placebo. 